Original Article

\title{
Effect of Eight Weeks of Aerobic Exercise before Cerebral Ischemia on Expression of NT-3 and TrkC in Male Rats
}

\author{
Mohtaram Yazdanian \\ (MSc) Department of Physical \\ Education and Sport Sciences, \\ Bojnourd Branch, Islamic Azad \\ University, Bojnord, Iran \\ Mahtab Moazzami (iD) \\ $(\mathrm{PhD})$ Department of Sport \\ Physiology, Faculty of Sport Sciences, \\ Ferdowsi University of Mashhad, \\ Mashhad, Iran \\ Mohammad Shabani \\ (PhD) Department of Sport Sciences, \\ University of Bojnord, Bojnord, Iran \\ Sadegh Cheragh Birjandi ic \\ $(\mathrm{PhD})$ Department of Sport Sciences, \\ Islamic Azad University, Bojnourd \\ Branch, Bojnourd, Iran \\ Corresponding author: Mahtab \\ Moazzami \\ Tel: +989153156705 \\ Email: mahtab.moazami@gmail.com \\ Address: Department, Exercise \\ Physiology, Physical Education and \\ Sports Sciences, Ferdowsi University \\ of Mashhad, Mashhad, Iran \\ Received: 2019/10/23 \\ Revised: 2019/12/11 \\ Accepted: 2019/12/17

\section{(c) (i) (9)} \\ This work is licensed under a Creative \\ Commons Attribution 4.0 License.
}

\begin{abstract}
Background and objectives: Cerebral ischemia causes irreversible structural and functional damage in certain areas of the brain, especially the hippocampus. Evidence indicates that physical exercise may reduce the damages caused by cerebral ischemia. The purpose of this study was to examine effects of eight weeks of exercise preconditioning on the expression of neurotrophin-3 (NT-3) and tyrosine kinase receptor C (TrkC) in the CA1 region of the hippocampus after cerebral ischemicreperfusion in male rats.
\end{abstract}

Methods: Twenty one male Wistar rats weighing 250-300 g were randomly selected and divided into three groups (healthy control, control+ischemia and exercise+ischemia). Rats in the exercise group ran on a treadmill, five days per week for eight weeks. Ischemia was induced by occlusion of both common carotid arteries for 45 minutes. In order to evaluate gene expression, real-time PCR was performed.

Results: The expression of NT-3 gene was significantly higher in the exercise+ischemia and control+ischemia groups than in the healthy control group $(\mathrm{P}<0.05)$. Moreover, TrkC gene expression was significantly lower in the exercise+ischemia and control+ischemia groups than in the healthy control group $(\mathrm{P}<0.05)$.

Conclusion: Exercise before the induction of ischemic stroke increases NT-3 expression but does not influence TrkC expression.

Keywords: Exercise Preconditioning, Ischemia/Reperfusion, NT-3, TrkC, Cell death 


\section{INTRODUCTION}

Stroke is a sudden neurological disorder following which the blood supply to the affected area of the brain becomes impaired and therefore cannot function properly. After ischemic stroke and capillary closure, revascularization occurs in the ischemic tissue, which is referred to as reperfusion. Reperfusion is associated with damages caused by the return of blood flow to the ischemic tissue. The lack of oxygen and nutrients, as a result of reperfusion, leads to inflammation and oxidative stress (1). The combination of initial and reperfusion injury determines the severity and outcomes of ischemic brain injury (2). On the other hand, certain areas of the brain and neuron types are more susceptible to cerebral ischemia, such as the pyramidal neurons of the hippocampal CA1 region. The hippocampus is an important area for learning and memory that consists of several areas, including the CA1 region $(3,4)$. Overexpression of some brain factors may cause regeneration or improve post-stroke brain functions. Two brain-derived neurotrophic factors; NT-3 and NT-4, are important for neurogenesis and survival of new neurons in the brain following acute ischemia (5). It is also believed that these factors can exert anti-apoptotic effects and enhance sensory recovery and neuronal stimulation after stroke (6). It is thought that the hippocampus is responsible for the simultaneous increase in brain-derived neurotrophic factor and NT-4 levels (7).

Among various neurotrophins, NT-3 is considered as an important facilitator of the survival and differentiation of neurons during development (8). The specific activity of NT-3 depends on the activity of its receptor, tyrosine kinase receptor $\mathrm{C}$ (TrkC) (9).

Evidence suggests that physical exercise may protect neurons against ischemic injury and reperfusion and improve neurological and functional rehabilitation (10). Exercise preconditioning also creates a neuroprotective effect that can increase neuronal survival against ischemic injury (11) by increasing the level of neurotrophins and strengthening the neurovascular system (12). However, the precise effect of exercise preconditioning on cerebral ischemia is not well known. Therefore, the aim of this study was to the effects of aerobic exercise on NT-3 and TrK-C expression in the hippocampus of rats before ischemia-reperfusion injury.

\section{MATERIALS AND METHODS}

Twenty one adult male rats (weighing 250$300 \mathrm{~g}$ ) were purchased from the Amol Pasteur Institute. The rats were kept in standard cages under 12:12 h light/dark cycle and at $22-24{ }^{\circ} \mathrm{C}$ with a free access to food and water. The rats were randomly divided into three groups: healthy control $(n=7)$, control + ischemia group $(\mathrm{n}=7)$ and ischemia + exercise group $(n=7)$. The study procedures were carried out at the Semnan University of Medical Sciences from $20^{\text {th }}$ of September to $30^{\text {th }}$ of November 2018. The study was approved by the ethics committee of the Semnan University of Medical Sciences (code: IR.SEMNAN.REC.1397.057) .Gene expression measurements were performed at the Pasargad Tissue and Gene Knowledge Laboratory of Tehran (Histogenotech Co, Iran).

Before the induction of ischemia, the exercise group trained on a treadmill, five sessions a week for eight weeks. In order to become familiar with the workout environment, the rats ran on a treadmill at $15 \mathrm{~m} / \mathrm{min}$ and zero incline for 10-15 minutes in the first two days. The training protocol consisted of running at $18 \mathrm{~m} / \mathrm{min}$ and zero slope for 20 minutes, five sessions a week. The exercise intensity was increased gradually until reaching the speed of $30 \mathrm{~m} / \mathrm{min}$, 10 degree incline, for 50 minutes in the eighth week.

According to a pilot study, closing common carotid arteries for 45 minutes leads to ischemia. Cresyl violet staining was performed to confirm ischemia and cell death. Surgery was performed by a skilled laboratory technician. First, the rats were anesthetized by intraperitoneal injection of ketamine/xylazine (40 $\mathrm{mg} / \mathrm{kg}$ ). Then, both common carotid arteries were released from the carotid plate and the vagus nerve was carefully removed from the carotid artery. Next, both common carotid arteries were blocked for 45 minutes using surgical clamps. The carotid arteries were released by removing the clamps and immediate restoration of blood flow. Reperfusion in the carotid arteries was confirmed by observation. During the surgery, the rectal temperature of the rats was 
controlled using a thermometer. After the surgery, the animals were kept in separate cages with free access to food and water for four days. Forty eight hours after the last training session, to eliminate the acute effects of exercise, the rats were anesthetized by intraperitoneal injection of ketamine (30-50 $\mathrm{mg} / \mathrm{kg}$ ) and xylazine $(3-5 \mathrm{mg} / \mathrm{kg}$ ). Head was separated from the neck by special scissors. The skull was ruptured using a razor and the brain was carefully removed. The brain was divided into two halves by a surgical razor. The hippocampus was separated from the limbic system, immediately frozen in liquid nitrogen and stored at $-80{ }^{\circ} \mathrm{C}$.

Seventy two hours after the induction of ischemia, the rats were anesthetized with ketamine/xylazine (40 $\mathrm{mg} / \mathrm{kg}$ ). The brain tissue was immediately removed, frozen in liquid nitrogen and stored at $-80{ }^{\circ} \mathrm{C}$. Real-time PCR was performed to evaluate gene expression. About $50 \mathrm{mg}$ of hippocampal tissue were homogenized for total RNA extraction using the QIAzol Lysis Reagent (Qiagen, Japan). In order to remove protein components, the mixture was centrifuged, mixed with chloroform at a ratio of 1 to 0.5 and heavily stirred for 15 seconds. RNA content was removed and mixed with isopropanol at a ratio of 1 to 0.5 and left at room temperature for 10 minutes.

Finally, the mixture was centrifuged at $12,000 \mathrm{~g}$ for 10 minutes at $4^{\circ} \mathrm{C}$. The resulting pellet containing total RNA was washed with ethanol. Concentration of total RNA was determined by calculating the ratio of absorbance at 260 and $280 \mathrm{~nm}($ A260/280).

To confirm quantitative expression of the desired genes, real-time PCR was carried out. Reverse transcriptase enzyme (Fermentas) was used to prepare a single-stranded cDNA using oligo-dT primers (MWG Biotech, Ebersberg, Germany).
The PCR reaction was carried out using SYBER Green PCR master mix (Applied Biosystems, Sequences Detection Systems, Focter City, CA) according to the manufacturer's protocol.

The sequence of primers is presented in table 1. GAPDH was used as a control gene.

The cycling conditions were as follows: 40 cycles of denaturation at $94{ }^{\circ} \mathrm{C}$ for 20 seconds, $58-60{ }^{\circ} \mathrm{C}$ for 30 seconds and $72{ }^{\circ} \mathrm{C}$ for 30 seconds.

The level of gene expression was measured using the $2-\Delta \Delta \mathrm{CT}$ method. Gene expression ratios were calculated by the comparative threshold cycle method using the following formula:

$$
\begin{gathered}
\mathrm{R}=2^{-(\Delta \Delta \mathrm{CT})} \\
\left.\Delta \Delta \mathrm{CT}=\left(\mathrm{CT}_{\text {target }}-\mathrm{CT}_{\text {refence }}\right)\right)_{\text {Time } \mathrm{X}}-\left(\mathrm{CT}_{\text {target }}-\mathrm{CT}_{\text {refence }}\right)_{\text {Time } 0}
\end{gathered}
$$

Standard and specific curves of each gene were plotted using at least two logarithmic concentrations in dilution order .Target gene expression was normalized to the reference gene and the expression level related to the healthy control group was considered as the calibrator.

$$
\text { Ratio }=\frac{\left(\mathrm{E}_{\text {target }}\right)^{\Delta \mathrm{CT} \text { target }}}{\left(\mathrm{E}_{\text {reference }}\right)^{\Delta \mathrm{CT}} \text { reference }}
$$

$\left(\Delta \mathrm{Ct}_{\text {refrence }}=\mathrm{Ct}_{\text {control }}-\mathrm{Ct}_{\text {treatment }}\right.$ and $\left.\Delta \mathrm{Ct}_{\text {target }}=\mathrm{Ct}_{\text {control }}-\mathrm{Ct}_{\text {treatment }}\right)$

In the above formula, E represents the degree of efficacy and is obtained by using the standard curve for the gene.

Data were expressed as mean and standard deviation. The Kolmogorov-Smirnov test was used to evaluate normality of data distribution. One-way ANOVA test was used for comparison of groups. Inter-group differences were evaluated using the Bonferroni post hoc test. All statistical analyses were carried out in the SPSS software (version 16) at significance of 0.05 .

Table 1. Sequence of primers used in this study

\begin{tabular}{cl}
\hline Genes & \multicolumn{1}{c}{ Primer sequence } \\
\hline \multirow{2}{*}{ NT-3 } & For: CTGTGGGTGACCGACAAGTC \\
& Rev: AAGTCAGTGCTCGGACGTAGG \\
\hline \multirow{2}{*}{ TrKG } & For: ACTTGTAATGGCTCTGGCTCTCC \\
& Rev: TGTCTTCGCTCGTCACATTCAC \\
\hline GAPHD & For: TGAAGGTCGGAGTCAACGGATTTGGT \\
& Rev: CATGTGGGCCATGAGGTCCACCAC \\
\hline
\end{tabular}



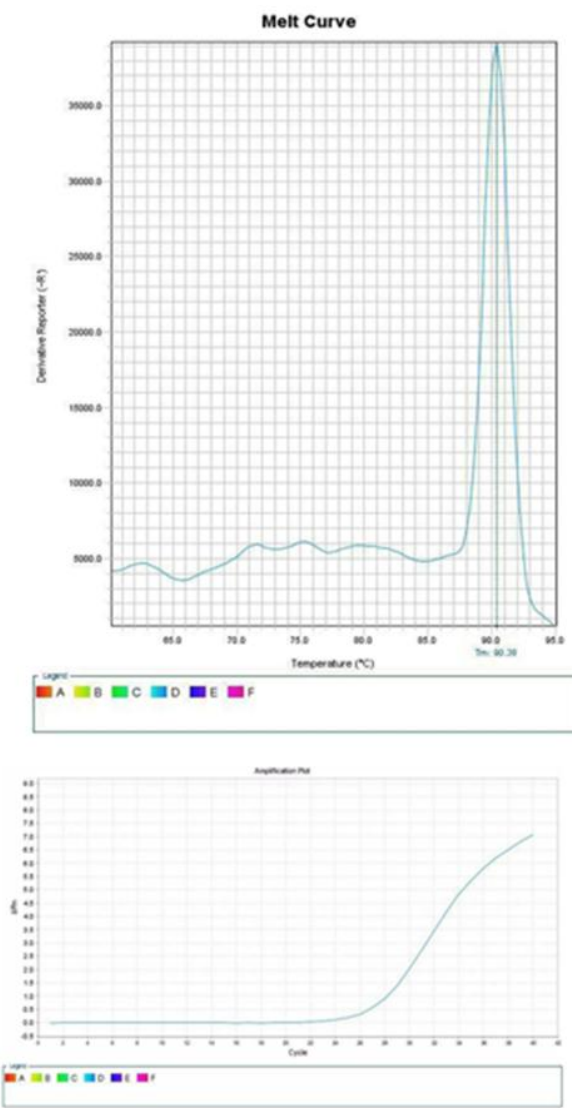

NT-3
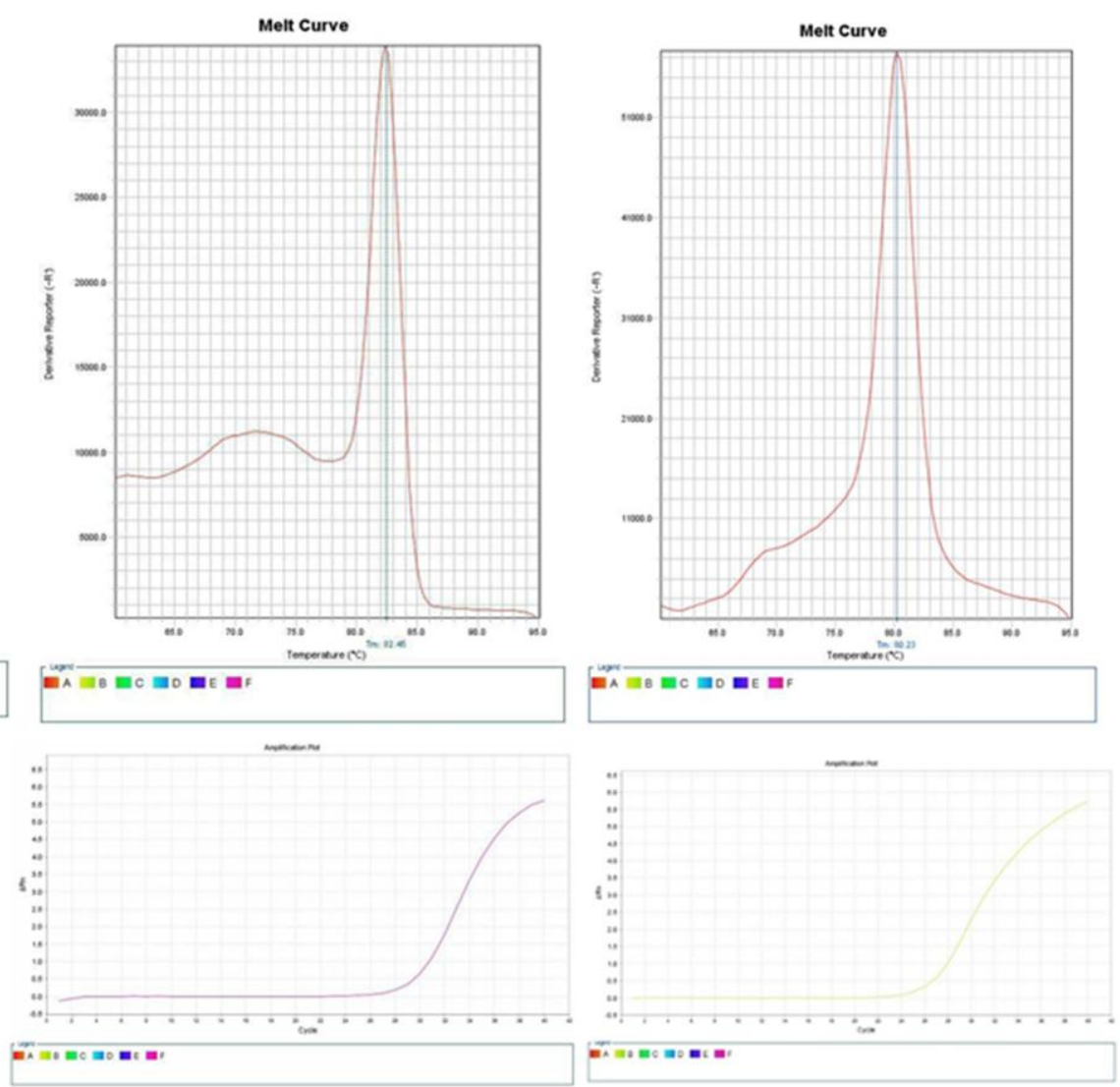

GapDH

\section{RESULTS}

The level of NT-3 gene expression in the exercise + ischemia group was significantly higher than that in the healthy control group. Moreover, NT-3 in the control + ischemia group was significantly overexpressed compared to the healthy control group ( $\mathrm{P}$ $<0.05$, Figure 1). The TrKC gene expression in the control + ischemia group was significantly higher than in the healthy control group ( $\mathrm{P}$ $<0.05$, Figure 2).

\section{DISCUSSION}

Stroke is a leading cause of death worldwide (13). Neurons in the CA1 region of hippocampus are the most sensitive to ischemia and hypoxia-induced damage. In this region, complete ischemia occurs five minutes after common carotid artery occlusion (14). Thus, this region is often used to assess brain tissue damage in both in vitro and in vivo investigations (15). Furthermore, following ischemic stroke and the subsequent cell death, a cascade of early molecular events begins, which aggravates the ischemic-induced damage (16). Stroke-induced cell death can be confirmed by the release of glutamate, which is a major pathway involved in cell death. The excessive activation of glutamate and its receptor may increase brain injury, especially in the hippocampal neurons (17-19). Other possible factors associated with increased neuronal cell damage following ischemic brain injury are inflammatory factors (20) and oxidative stress, which can exacerbate the damage caused by ischemia in the reperfusion phase (21).

There are contradictory results regarding the effect of different rehabilitation approaches for stroke patients (22). The low success rate of some stroke prevention approaches may be due to the fact that some inflammatory factors are produced after ischemic stroke $(11,23)$. However, exercise can have neuroprotective effects against ischemic injury and reperfusion by reducing the risk factors. Studies revealed that exercise preconditioning can decrease the release of glutamate and the overexpression of glutamate receptors, thus alleviating brain injury after stroke $(24,25)$. 
The protective effects of physical activity may be related to upregulation of some neurotrophins. Neurotrophins are widely found in the brain due to their essential role in the growth and differentiation of neuronal cells (26). In this regard, Chan et al. demonstrated that increasing the volume of neurotrophins reduces infarction in mice with cerebral ischemia (27). Moreover, it has been stated that the expression of blood and brain neurotrophins increases in human and animal subjects following different sports activities $(28,29)$. In line with our findings, a study reported an increase in NT-3 gene expression after acute running one day and five days on the treadmill in rats (30). On the other hand, another study reported no change in NT-3 and TrKC expression in the soleus muscle following three days of exercise (31).

Exercise enhances neuronal activity and secretion of neurotrophic factors, which subsequently creates more neuroprotection against ischemic damage $(11,32)$. In this regard, Jia et al. demonstrated that exercise preconditioning can protect the neuronal branches in the striatum against ischemic injury (33). In a study carried out on rats, Schäbitz et al. indicated that exercise preconditioning significantly increased neurotrophic endogenous levels, providing more neuroprotection against ischemic injury (6).

Figure 1. Effect of exercise preconditioning on NT-3 gene expression after induction of ischemia in different groups

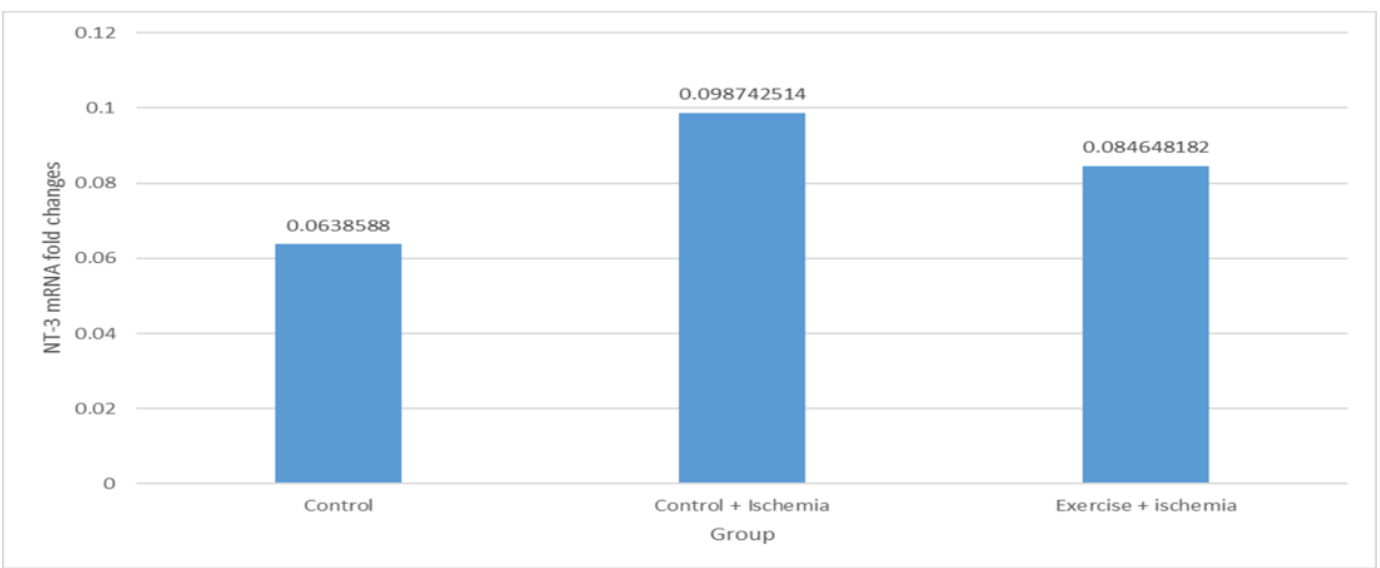

Figure 2. Effect of aerobic exercise on TrKC gene expression after induction of ischemia in different groups

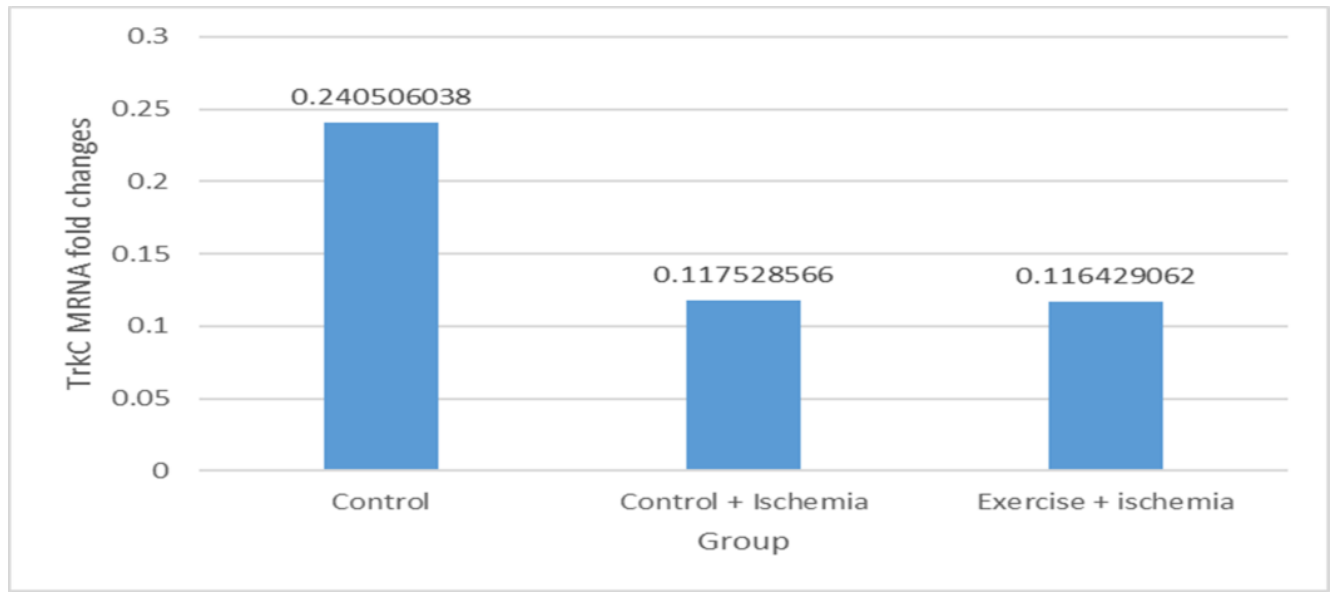




\section{CONCLUSION}

Overall, our findings suggest that exercise preconditioning increases the expression of NT3, which contributes to neuroprotection against the harmful effects of ischemic stroke and to faster recovery of the hippocampal cells after ischemic stroke. In addition, exercise before induction of ischemia has no positive effect on TrkC expression. However, further studies are needed to understand the effect of aerobic exercise training before induction of ischemia on the expression of neurotrophic factors.

\section{ACKNOWLEDGEMENTS}

We would like to express our sincere appreciation to all people who helped us in this project.

\section{CONFLICT OF INTEREST}

All authors declare that there is no conflict of interest.

\section{REFERENCES}

1.Elzawahry H, Hernandez- Frau PE, Behrouz R, Clark MW. Reperfusion Injery in Stroke. Emedicine. 2011. Available form: http://emedicine.medscape.com/article/11624337overview. Accessed Agust 08, 2013.

2. Yokobori S, Mazzeo AT, Hosein K, GajavelliS, Dietrich WD, Bullock MR. Preconditioning forTraumatic Brain Injury. Transl Stroke Res. 2013; 4(1): 25-39. https://doi.org/10.1007/s12975-012-0226-1.

3. Mustoe T. Understanding chronic wounds: a unifying hypothesis on their pathogenesis and implications for therapy. Am J Surg. 2004; 187:65S-70S. https://doi.org/10.1016/S0002-9610(03)00306-4.

4. Kawaguchi C, Takizawa S, Niwa K, Iwamaoto T, Kuwahira I, Kato H, Shinohara Y. Regional vulnerability to chronic hypoxia and chronic hypoperfusion in the rat brain. Apathophysiology. 2002; 8:249253.https://doi.org/10.1016/S0928-4680 (02)00014-7.

5. Sun Y, Jin K, Xie L, Childs J, Mao XO, Logvinova A, et al. VEGF-induced neuroprotection, neurogenesis, and angiogenesis after focal cerebral ischemia. J Clin Invest. 2003 111:1843-51.

https://doi.org/10.1172/JCI200317977.

6. Schäbitz W-Rd, Steigleder T, Cooper-Kuhn CM, Schwab S, Sommer C, Schneider A, et al. Intravenous brain-derived neurotrophic factor enhances poststroke sensorimotor recovery and stimulates neurogenesis. Stroke. 2007; 38(7): 2165-72. https://doi.org/10.1161/STROKEAHA.106.477331.

7. Ferreira AFB, Real CC, Rodrigues, AC, Alves AS, Britto LRG. Short-term, moderate exercise is capable of inducing structural, bdnf-independent hippocampal plasticity. Brain research. 2011; (1425): 111-122. https://doi.org/10.1016/j.brainres.2011.10.004.

8. Lessmann V, Gottmann $\mathrm{K}$, Malcangio $\mathrm{M}$. Neurotrophin secretion: current facts and future prospects. Progress in neurobiology. 2003; 69(5): 34174. https://doi.org/10.1016/S0301-0082(03)00019-4.
9. Cohen-Cory S, Kidane AH, Shirkey NJ, Marshak S. Brain-derived neurotrophic factor and the development of structural neuronal connectivity. Dev Neurobiol. Apr. 2010; 70(5):271-88. https://doi.org/10.1002/dneu.20774.

10. Davis W, Mahale S, Carranza A, Cox B, Hayes K, Jimenez D, et al. Exercise pre-conditioning ameliorates blood-brain barrier dysfunction in stroke by enhancing basal lamina. Neurol Res. 2003; 29(4): 382-7. https://doi.org/10.1179/016164107X204701.

11. Liebelt B, Papapetrou P, Ali A, Guo M, Ji X, Peng $\mathrm{C}$, et al., Exercise preconditioning reduces neuronal apoptosis I $n$ stroke by up-regulating heat shock protein70 (heat shock protein-72) and extracellular-signalregulated-kinase 1/2. Neuroscience. 2010; 166(4): 10911100.

https://doi.org/10.1016/j.neuroscience.2009.12.067.

12. Kochanski R, Dornbos D, Ding Y. Neuroprotection and physical preconditioning Exercise, Hypothermia, and hyperthermia. Innate Tolerance in the CNS. 2013; 105-131. https://doi.org/10.1007/978-1-4419-9695-4_5.

13. Bang OY. Multimodal MRI for ischemic stroke: from acute therapy to preventive strategies. J Clin Neurol. 2009; 5(3): 107-119. https://doi.org/10.3988/jcn.2009.5.3.107.

14. Williams-Karnesky RL, Stenzel-Poore MP. Adenosine and stroke: maximizing the therapeutic potential of adenosine as a prophylactic and acute neuroprotectant. Current neuropharmacology. 2009; 7(3):

217-27. https://doi.org/10.2174/157015909789152209.

15. Broughton BR, Lim R, Arumugam TV, Drummond GR, Wallace EM, Sobey CG. Post-stroke inflammation and the potential efficacy of novel stem cell therapies: focus on amnion epithelial cells. Frontiers in cellular neuroscience. $2013 ; \quad 6$ : 66. https://doi.org/10.3389/fncel.2012.00066.

16. Jia J, Hu YS, Wu Y, Yu HX, Liu G, Zhu DN, et al. Treadmill pre-training suppresses the release of glutamate resulting from cerebral ischemia in rats. Exp Brain Res. 2010; 204(2):173-9. https://doi.org/10.1007/s00221-010-2320-5.

17. Moskowitz MA, Lo EH, Iadecola C. The science of stroke: mechanisms in the search of treatments. Neuron. 2010; $\quad 67 \quad$ (2): $\quad 181-98$. https://doi.org/10.1016/j.neuron.2010.07.002.

18. Sattler R, Tymianski M. Molecular mechanisms of glutamate receptor-mediated excitotoxic neuronal cell death. Mol neurobiolo. 2001; 24(1-3): 107-29. https://doi.org/10.1385/MN:24:1-3:107.

19. Saito K, Suyama K, Nishida K, Sei Y, Basile AS. Early increases in TNF- $\alpha, I L-6$ and IL-1 $\beta$ levels following transient cerebral ischemia in gerbil brain. Neuroscience letters. 1996; 206(2-3):149-52. https://doi.org/10.1016/S0304-3940(96)12460-5.

20. Danton GH, Dietrich WD. Inflammatory mechanisms after ischemia and stroke. J Neuropathol Exp Neurol. 2003; 62(2):127-36 https://doi.org/10.1093/jnen/62.2.127.

21. Dirnagl U, Macleod MR. Stroke research at a road block: the streets from adversity should be paved with meta-analysis and good laboratory practice. British journal of pharmacology. 2009; 157(7): 1154-6. https://doi.org/10.1111/j.1476-5381.2009.00211.x. 
22. Zhao B-Q, Tejima E, Lo EH. Neurovascular proteases in brain injury, hemorrhage and remodeling after stroke. Stroke. 2007; 38(2): 748-52. https://doi.org/10.1161/01.STR.0000253500.32979.d1.

23. Page-McCaw A, Ewald AJ, Werb Z. Matrix metalloproteinases and the regulation of tissue remodelling. Nat Rev Mol Cell Biol. 2007; 8(3): 221-33. https://doi.org/10.1038/nrm2125.

24. Zhang F, Jia J, Wu Y, Hu Y, Wang Y. The effect of treadmill training pre-exercise on glutamate receptor expression in rats after cerebral ischemia. International journal of molecular sciences. 2010; 11(7): 2658-69. https://doi.org/10.3390/ijms11072658.

25. Laufs U, Werner N, Link A, Endres M, Wassmann S, Jürgens K, et al. Physical training increases endothelial progenitor cells, inhibits neointima formation, and enhances angiogenesis. Circulation. 2004; 109(2): 220-6. https://doi.org/10.1161/01.CIR.0000109141.48980.37.
26. Deister C, Schmidt CE. Optimizing neurotrophic factor combinations for neurite outgrowth. J Neural Eng. 2006; 3(2): 172. https://doi.org/10.1088/17412560/3/2/011.

27. Kochanski R, Dornbos D, Ding Y. Neuroprotection and physical preconditioning: Exercise, Hypothermia, and hyperthermia. Innate Tolerance in the CNS: Springer; 2013; 105-31. https://doi.org/10.1007/978-14419-9695-4_5.

28. Chan K-M, Lam D-TN, Pong K, Widmer HR, Hefti F. Neurotrophin- $4 / 5$ treatment reduces infarct size in rats with middle cerebral artery occlusion. Neurochemical $\begin{array}{llll}\text { research. } & \text { 1996; } & \text { 21(7): }\end{array}$ https://doi.org/10.1007/BF02532298.

29. Zoladz JA, Pilc A. The effect of physical activity on the brain derived neurotrophic factor: from animal to human studies. J Physiol Pharmacol. 2010; 61(5): 53341.

\section{How to Cite:}

Yazdanian M, Moazzami M, Shabani M, Cheragh Birjandi S. [Effect of Eight Weeks of Aerobic Exercise before Cerebral Ischemia on Expression of NT-3 and TrkC in Male Rats ]. mljgoums. 2020; 14(5): 35-41. DOI: 10.29252/mlj.14.5.35 